\title{
Sobre Avaliação, Pesquisas e Políticas Públicas: considerações de alguns pesquisadores brasileiros
}

\author{
LOLA YAZBECK ${ }^{1}$ \\ Universidade Federal de Juiz de Fora - MG \\ yazbeck@terra.com.br
}

\begin{abstract}
Resumo
O texto reproduz as entrevistas nas quais se procurou perceber as opiniões de pesquisadores brasileiros sobre a trajetória dos temas estudados na sociologia da educação, a correspondência entre as questões levantadas pelas pesquisas educacionais, o uso dos resultados das avaliações, como também a possível influência dos resultados das avaliações na implementação das políticas públicas educacionais. As questões foram propostas a alguns pesquisadores do campo educacional e aos coordenadores de projetos avaliativos do Brasil.
\end{abstract}

Palavras-chave: avaliação, pesquisas em sociologia da educação, políticas públicas educacionais.

\section{Resumen}

El texto reproduce algunas entrevistas en las que se intentó comprender las opiniones de investigadores brasileños sobre la trayectoria de los temas estudiados por la sociología de la educación, la correspondencia entre los temas relevados por las investigaciones educativas, el uso de los resultados de las evaluaciones, así como también las posibles influencias de estos resultados en la implementación de las políticas públicas educativas. Las cuestiones fueron propuestos a algunos investigadores del campo de la educación y a los coordinadores de proyectos evaluativos de Brasil.

Palabras-clave: evaluación, investigaciones en sociología de la educación, políticas públicas educativas.

\begin{abstract}
This article reproduces interviews which attempted to sample the opinions of Brazilian researchers on the development of topics studied in the field of Educational Sociology, the correspondence between issues raised by educational research, the use of evaluation results, as well as the possible influence these results may have on implementing public policies in Education. The questions were submitted to some researchers in the educational field and to coordinators of evaluative projects in Brazil.
\end{abstract}

Key words: evaluation, research in Educational Sociology, public policies in Education.

1 Professora dra. Dalva Carolina de Menezes Yazbeck. 


\section{O TRAJETO DO TRABALHO}

O artigo é parte de uma pesquisa comparativa sobre a institucionalização da avaliação educacional, desenvolvida no estágio de pós-doutorado, como bolsista da Coordenação de Aperfeiçoamento de Pessoal de Nível Superior (Capes), que teve como referência as instituições governamentais: Ministère de l'Éducation Nationale/Direction de la Programmation et du Développement (MNE/DPD) e o Instituto Nacional de Estudos e Pesquisas Educacionais Anísio Teixeira (Inep), responsáveis pelas políticas de avaliação da educação básica na França e no Brasil ${ }^{2}$.

A intenção de conversar com os pesquisadores que dedicam seus trabalhos à educação e com os coordenadores de projetos avaliativos brasileiros foi, em linhas gerais, o de conhecer as opiniões sobre os caminhos percorridos a respeito dos temas de estudos, principalmente na última década, bem como acerca da possível influência de seus trabalhos na formulação das políticas públicas. Não se poderia deixar de perguntar sobre o uso de indicadores fornecidos pela avaliação da educação básica.

Para obter as opiniões dos pesquisadores e coordenadores de projetos avaliativos, optou-se por enviar um questionário a um grupo representativo de profissionais dos dois países. A escolha dos entrevistados foi intencional, com base na literatura e/ou na indicação de colegas. No caso dos pesquisadores brasileiros, a solicitação para participarem da pesquisa foi feita por meio da internet, e os questionários aplicados em agosto e setembro de $2001 .{ }^{3} \mathrm{O}$ convite foi precedido do envio de uma carta de apresentação pessoal e de um resumo da pesquisa, onde se descrevia a intenção de estudar as políticas públicas de avaliação na França e no Brasil sem perder de vista o contexto histórico, social e político dos dois países. Levava-se em conta os fatores intra e extra-escolares, a importância da pesquisa acadêmica e sua influência nas políticas públicas nos anos 1990. Na ocasião, foi solicitada ainda aos entrevistados a autorização para publicar suas repostas parcialmente ou na íntegra.

As questões propostas foram semelhantes para os dois grupos de pesquisadores. Entretanto, dadas as diferenças estruturais das línguas, algumas questões tiveram de ser desdobradas, mantendo-se, contudo, o seu sentido principal. Para cada grupo de entrevistados foram convidados em torno de vinte profissionais. No grupo de entrevistados brasileiros,

2 As entrevistas foram realizadas no $2^{\circ}$ semestre de 2001, e o relatório da pesquisa aprovado pela Capes no final de 2002.

3 Os pesquisadores franceses foram entrevistados pessoalmente, de setembro a novembro, em Paris e cidades vizinhas. Nos dois casos, buscou-se evitar o período das férias acadêmicas dos respectivos países. 
obteve-se um percentual de $60 \%$ de respostas e apenas uma recusa formal. Do grupo francês, também $60 \%$ responderam ao questionário enviado. De modo semelhante, entre os entrevistados dos dois países, alguns justificaram a impossibilidade de responder o questionário no tempo proposto e outros enviaram textos com comentários pertinentes às questões.

Os questionários devolvidos pelos pesquisadores possibilitaram registros para futuros comentários, embora nem todas as respostas tenham sido computadas - além de opiniões repetidas, muitas delas estavam pouco claras ou mesmo lacônicas.

Deve ser endereçada a mim, uma crítica especialmente quanto à concentração geográfica dos entrevistados brasileiros nas regiões de São Paulo e Rio de Janeiro. Tal fato se deve à demora em obter contato com pesquisadores do Nordeste e do Norte do país ${ }^{4}$.

Do relatório de pesquisa apresentado e aprovado pela Capes pude retirar elementos para alguns artigos que foram publicados em diferentes periódicos que não estão isentos de conter dados nomeados neste artigo. Entretanto, fazer um artigo específico com os entrevistados brasileiros tem a intenção primordial de socializar as interessantes opiniões de colegas e poder incentivar uma reflexão mais ampla sobre os temas tratados.

\section{A OPINIÃO DOS PESQUISADORES}

A primeira questão dirigida ao grupo de pesquisadores brasileiros foi relativa à priorização dos temas intra-escolares a partir do final dos anos 1980. Foi solicitado ao entrevistado também a nomeação de temas que devam ser ou devam continuar sendo investigados pela Sociologia da Educação.

\footnotetext{
4 Como exemplo o Estado de Pernambuco. Justifica-se por ter sido um dos poucos Estados que, ainda na década de 80, começou a construir um sistema próprio de avaliação. Tratavase de um sistema independente, constituído de poucas questões e aplicado a alunos de escolas de primeiro grau - da $1^{\mathrm{a}}$ e $4^{\mathrm{a}}$ séries na disciplina de Português (compreensão de leitura), e da $3^{\mathrm{a}}$ série na disciplina de Matemática (soma e subtração). Esse sistema foi implementado pela primeira vez em 1987, na região do sertão, e posteriormente na região metropolitana de Pernambuco. Em 1989, uma amostra dos alunos do Estado foi submetida a testes que tinham, então, uma função diagnóstica. Os resultados foram utilizados pela Secretaria de Educação para a elaboração de um extenso programa de formação e atualização dos professores do Estado de Pernambuco, que foi articulado à universidade de origem da professora Silke Weber, que atuou como Secretária de Educação do Estado de 1987 a 1991 e de 1995 a 1998, e envolveu professores de diversas faculdades da UFPe e de outras universidades do país (Cf. Bonamino, 2000, p. 95).
} 
No geral, as posições registradas pelos entrevistados quanto a esta questão são bem homogêneas. Gaudêncio Frigotto acredita que

[...] efetivamente a Sociologia da Educação, tomada em sentido amplo, e não só no Brasil, priorizou temáticas muito específicas vinculadas às dimensões intraescolares. Alguns poucos estudos mais amplos ocupam-se da sociologia do currículo numa perspectiva mais ampla e de problemas de relações de poder. Até onde minha análise alcança, esta tendência é verificada em outros campos disciplinares e isto decorre, em boa medida, direta ou indiretamente, do avanço das posturas metodológicas de inspiração pós-moderna, do multiculturalismo e do neoliberalismo. Estas perspectivas, por caminhos diversos, afirmam-se individualistas e particularistas. Uma das justificativas para essa ênfase situa-se na crítica aos referenciais de análise mais clássicos, tidos como metanarrativas e visões fundamentalistas.

Frigotto nomeia alguns temas que merecem ser investigados:

(1) as bases socioeconômicas e culturais da produção social dos sujeitos que freqüentam a escola e suas relações com o processo de socialização e de conhecimento que se efetiva na escola; (2) as relações de classe e de poder e os processos educativos; (3) as mudanças metabólicas da sociabilidade do capital, a crise dos Estados nacionais e o desmonte institucional da escola como esfera pública e a perspectiva privatista do conteúdo escolar.

Embora concorde com a afirmação proposta pela questão, principalmente no que tange ao conhecimento produzido no Brasil nos anos 80, Sandra Zákia Souza ${ }^{5}$ acredita que é possível identificar, nos anos 90, ao lado do desenvolvimento de pesquisas direcionadas a questões intraescolares, investigações voltadas para a análise de como vêm sendo formuladas e implementadas as politicas educacionais, em uma perspectiva local comparada, considerando os novos princípios em que se assentam tais políticas e seus novos contornos, em um contexto de redefinição do Estado.

Quanto aos temas que devam continuar sendo investigados, a pesquisadora destaca:

5 Em sua tese de doutorado a autora dedica um item à abordagem da trajetória da pesquisa educacional através das suas ênfases, onde comenta que durante os anos 80 tem-se na pesquisa educacional a valorização do conhecimento sobre o funcionamento interno da escola, procurando desvelar mecanismos, regras, relações, verdades rituais, silêncios, enfim, princípios e práticas que expressam relações de dominação, mas que contêm possibilidades emancipadoras (p. 87). Sandra Zákia Souza situa essa perspectiva de análise da educação em uma reconcepção do próprio Estado capitalista, superando-se uma visão mecanicista do Estado. 
a avaliação educacional, voltando-se não só para as práticas vigentes no interior das escolas, mas também para os impactos que as avaliações sistêmicas têm gerado no cotidiano escolar; os processos de inclusão escolar de alunos que apresentam necessidades educacionais especiais; as novas formas de trabalho escolar que vêm sendo estimuladas sob a denominação de autonomia da escola.

Na opinião de Ivany Pino, os anos 80 foram marcados por um deslocamento de olhares da Sociologia da Educação, das macros ou grandes questões das políticas e sistemas

[...] para o interior das escolas, o currículo, sempre perseguindo, a meu ver, a relação da educação com a sociedade, mais precisamente, a função social da escola. A Nova Sociologia da Educação surgida nos países anglo-saxônicos está na base deste deslocamento e entre seus autores encontram-se Bourdieu e Bernenstein, mas também a crítica de não estar suficientemente apoiada em Gramsci. Aí tem um panorama teórico muito diverso, no qual os autores ressaltam as teorias de reprodução, a questão cultural etc. Os neomarxistas americanos, na época, voltaram seus olhares também para a função social da escola, vista no seu interior, depois de superarem (Apple, sobretudo em relação a Boeles e Jenkis) a teoria da correspondência, e alargaram a questão do poder para a cultura (etnia e gênero), sem perder a dimensão de classe social".

Assim, a autora considera que a afirmação posta pela questão não coloca com justeza a dimensão deste novo olhar que parte do interior da escola e volta-se para a vida social na indagação da sua função. Quanto aos temas que considera importantes, Ivany Pino destaca: saberes e conhecimento escolares, currículo, e a tríade recortando classe social/gênero e etnia/a questão da desigualdade.

De forma semelhante, Iza Locatelli ${ }^{6}$ afirma:

nas décadas de 80 e 90 os estudos micro tiveram grande importância e serviram para que se pudesse conhecer melhor o interior das escolas. Ao final dos anos 90 retomou-se, sob outra ótica, questões relacionadas à cultura organizacional das escolas, clima da escola, representações dos professores sobre seu fazer pedagógico. Estes temas têm sido trabalhos na literatura ibero-americana (vide Nóvoa e seu grupo).

Para a pesquisadora, este assunto deve continuar sendo estudado, já que se percebe ser a escola, na realidade, o lugar onde as mudanças acontecem.

${ }^{6}$ A tese de doutorado de Iza Locatelli, defendida na PUC-RJ em 1998, aborda vários aspectos da cultura organizacional das escolas. 
Aparecida Néri de Souza concorda que, de fato,

[...] houve um movimento (a partir da Nova Sociologia da Educação, de forte tradição inglesa) de análises sobre a escola e que no Brasil este movimento coincide com a organização dos cursos de pós-graduação em Educação. A escola ora é tratada como instituição, ora como organização complexa. A referência para estes estudos é o crescimento da educação escolarizada (daí a perspectiva institucional), a heterogeneidade sociocultural dos alunos (que abarca as temáticas propostas na questão formulada e que de certa forma é a preocupação dos franceses nas discussões entre desigualdades socioculturais e escolarização) e acho que há no seu "etc." a referência dos estudos às políticas educacionais. Se essas temáticas estão atachadas à educação básica, há uma presença forte da Sociologia da Educação nos estudos sobre a universidade (esse tipo de pesquisa é realizado por aqueles que estão ligados institucionalmente aos cursos de ciências sociais, e não às faculdades de Educação), veja os trabalhos do GT Educação e Sociedade da Associação Nacional de Pós-Graduação e Pesquisa em Ciências Sociais (Anpocs). A Sociologia da Educação descobriu a escola (básica) e parece ter dificuldades em fazer análises e historiar as relações entre sociedade e educação (que sempre foi nossa tradição). Diferentemente daqueles que trabalham com a temática universidade e suas relações com os "projetos" de desenvolvimento, modernização (ou que nome isso venha a ter). Finalmente, uma pequena observação: os estudos sobre professores são muito mais pedagógicos que sociológicos; o trabalho docente é entendido somente na dimensão das práticas pedagógicas (não se fala das relações entre as condições e a organização do trabalho docente e das relações sociais a que ele é submetido).

Quanto aos temas que devam ser ou devam continuar sendo investigados pela Sociologia da Educação, Aparecida Néri de Souza sugere:

(1) as desigualdades sociais e culturais em face da escola (analisadas de dentro da escola, mas a análise dessas desigualdades vista como resultante das mudanças sociais, culturais e econômicas); (2) o trabalho do professor para além das práticas pedagógicas, como métier, profissão, ocupação etc. (penso que em relação ao professor há mais rupturas que permanências); (3) os estudos sobre família e escola poderiam incorporar os jovens (inserção, emprego), ou as representações que a família (pais ou alunos) elabora sobre a escola, as demandas ou os movimentos sociais por educação escolar, isto é, poderiam se ampliar e sair da escola.

Para Luís Carlos Freitas tem havido um grande esforço para examinar aspectos intra-escolares. No entanto, ele ressalta que este não é o problema,

[...] pois também é verdade que a explicação dos fatores intra-escolares, em suas ligações com o ambiente social da escola, pelo menos para alguns, foi igualmente enfatizada. O risco maior advém das vertentes pós-modernas que, numa atitude 
antidialética, isolam a chamada "diferença" e enfatizam estudos que tratam de maneira isolada tais fatores intra-escolares e, não contentes com isso, mas de forma coerente com o que pensam, disparam contra as análises globais que situam e resituam os fatores intra-escolares. Em resumo, não há futuro em nenhum estudo destes dois pólos isolando-se um deles. Talvez tenhamos que voltar a Hegel e reaprender a dialética.

Quanto aos temas a serem investigados, esse pesquisador destaca $a$ questão dos fins da educação e seu condicionamento pelos sistemas sociais (a produção social da forma escola, por exemplo), numa perspectiva de superação; a sociologia dos currículos escolares (a produção social das disciplinas e seus conteúdos, por exemplo) e a questão da educação em face da desigualdade.

Para Alicia Bonamino, a tendência de priorização dos temas intraescolares, a partir do final dos anos 1980, é dominante na Sociologia da Educação contemporânea, decorrente do acesso massivo da população à educação básica, que fez com que a questão da escolarização deixasse de ser um problema quantitativo para se transformar, paulatinamente, a partir do pós-guerra, em uma questão qualitativa.

Quando indagados sobre se as pesquisas em ciências sociais voltadas à educação, principalmente nas duas últimas décadas, têm conseguido influir nas políticas de educação básica, os entrevistados manifestaram diferentes posições. Para Gaudêncio Frigotto,

[...] no caso brasileiro, se influenciou, foi por via indireta. No Brasil vivemos aquilo que, numa densa análise, Renato Janine Ribeiro denomina de a "sociedade contra o social". O econômico ou o mercado e o capital são a sociedade e o social é a pobreza. Como nunca antes, a educação básica no Brasil hoje está pautada por um economicismo obscurantista e arrogante. As noções ideológicas de "competências, habilidades, empregabilidade" (ou, como nos pareceres, trabalhabilidade ou laborabilidade) explicitam um processo de profunda mercantilização do pensamento educacional. Os mecanismos de avaliação assim denominados evidenciam este viés. Não é por acaso que os "intelectuais coletivos" que orientam o campo educativo no Brasil, no plano organizativo e pedagógico, são hoje os organismos internacionais.

$\mathrm{Na}$ mesma linha de pensamento, Iza Locatelli percebe que os trabalhos na área da Sociologia da Educação têm colaborado para maiores reflexões em educação. No entanto, como é comum em nosso país, trata-se de discussões acadêmicas que não atingem a formação inicial e continuada ou a ação dos professores. Portanto, a meu ver, têm tido pouca referência na mudança efetiva da escola brasileira. 
Para Sandra Zákia Souza, este é um debate complexo. Diz a pesquisadora:

Nos limites das considerações aqui registradas quero destacar apenas dois pontos, dentre tantos outros que poderiam ser abordados: (a) a literatura sobre a utilização das pesquisas na formulação e reformulação das políticas públicas tem evidenciado que este processo não se dá de modo linear, demandando, com raras exceções, um tempo para que os gestores incorporem eventuais contribuições das pesquisas no delineamento das políticas; (b) a incorporação das contribuições das pesquisas muitas vezes se evidencia tanto no plano da legislação como nos planos e programas governamentais. No entanto, há que se observar como se deu tal incorporação, ou seja, como essas contribuições foram interpretadas à luz do programa governamental mais amplo, bem como que condições concretas foram viabilizadas para tornar realidade uma dada proposta que emerge das investigações.

Na opinião de Creso Franco, a especificação restrita da "Sociologia da Educação" torna a resposta difícil, pois exige um balanço que a distinga de outras áreas correlatas. O pesquisador não se sente em condições de pensar acuradamente sobre a questão, mas faz algumas ponderações:

Desde a década de 80 um número expressivo de intelectuais da "grande área das ciências sociais" (educadores de diversas especialidades, inclusive da Sociologia da Educação, economistas etc.) tem ocupado posições de destaque na gestão de sistemas educacionais. Creio que não haverá controvérsia se admitirmos que esses intelectuais levam suas bagagens intelectuais e de pesquisa para os postos em que atuam; muito mais complicado é avaliar os diversos padrões de relação estabelecidos entre os campos acadêmicos e políticos e, conseqüentemente, entre pesquisa e construção de políticas educacionais.

Aparecida Néri de Souza concorda que as pesquisas têm influenciado as políticas de educação básica. Para ela,

[...] a produção de políticas educacionais tem se apropriado da pesquisa buscando legitimidade para a formulação de determinadas concepções de escolarização, currículo, nas reformas educacionais em curso. O poder público (aqui entendido também como os grupos de trabalho que organizam os projetos, os assessores etc.) atribui às pesquisas (que alguns deles realizaram) um caráter de universalidade que legitima o poder exercido em nome deste "sabe". Creio que há uma redução da política à chamada "competência técnica" que considera que só é justo o poder que é exercido em nome deste "saber", supostamente universal. Por exemplo, grande parte dos estudos sobre o ensino médio (que sempre apontavam para a falta de "projeto") e sobre egressos dos cursos técnicos contribuiu para legitimar a reforma do ensino médio e profissional. Os estudos sobre as práticas pedagógicas dos professores deslocaram as origens das desigualdades sociais para 
dentro da sala de aula e o professor tem sido responsabilizado (nas políticas) pelas mazelas do "atraso educacional brasileiro".

Quando indagados sobre se a avaliação educacional realizada nas duas últimas décadas, tanto no âmbito estadual quanto no âmbito federal, tem oferecido e divulgado indicadores que permitam analisar a real situação da educação básica, e se ela indica as principais demandas sociais, os entrevistados também apresentaram posições bastante diferenciadas. Segundo Iza Locatelli,

[...] a cultura de avaliação no Brasil é recente. Temos apenas uma década de avaliações sistemáticas. Ainda assim, já se dispõe, através do Saeb, do Enem e do Provão (atual Enade), de um sistema de avaliação. Dados são coletados, resultados são divulgados. No entanto, ainda que se tenha podido detectar fatores associados ao desempenho da escola brasileira, não se conseguiu mudar efetivamente esta escola. Níveis de repetência e evasão ainda são altos, embora todos os estudos e pesquisas realizados pelo Saeb demonstrem que os niveis de desempenho dos alunos decrescem em função do número de anos de repetência. Tem-se feito muito, mais ainda há muito a realizar.

Sandra Zákia Souza, por sua vez, comenta sobre a direção dada às avaliações educacionais:

No Brasil, as iniciativas de avaliação dos sistemas escolares - em larga escala - são recentes, tendo sido iniciadas a partir dos anos 90, tanto em âmbito federal quanto estadual. Contamos ainda com poucos estudos empíricos que nos permitam aquilatar seus impactos sobre a educação básica. As análises disponíveis, em sua maior parte, têm se voltado para considerações sobre a racionalidade que vem direcionando tais avaliações, alertando que, tal como vêm sendo conduzidas, sob os auspicios da classificação e seleção, elas incorporam, conseqüentemente, a exclusão como inerente aos seus resultados, o que é incompatível com o direito de todos à educação.

A pesquisadora ressalta, no entanto, o aprimoramento crescente dos levantamentos de dados sobre a educação básica disponibilizados tanto por órgãos federais como estaduais, os quais não decorrem das iniciativas de avaliação, mas dos procedimentos de organização e atualização das estatísticas educacionais.

Quando indagada sobre se a avaliação educacional aponta e divulga as principais demandas sociais em relação à educação básica, Sandra Zákia Souza respondeu que esta não tem sido uma preocupação dos procedimentos e instrumentos usualmente utilizados na avaliação. Nos limites de minha observação, não identifiquei procedimentos direcionados ao levantamento de demandas sociais como integrantes das sistemáticas de avaliação. 
Creso Franco em princípio concorda que as avaliações têm fornecido indicadores que permitem analisar a real situação da educação básica, mas com severas limitações. Nesse sentido, indica o trabalho de sua autoria (Franco, 2001), chamando a atenção para o fato de que embora o texto focalize o Saeb, o raciocínio nele desenvolvido se aplica a quase todos os projetos estaduais. Franco ressalva, entretanto, que os problemas lá relatados não se aplicam ao Saresp que, surpreendentemente, não tira proveito disso. Segundo ele, as análises baseadas em dados do Saresp ficam aquém das suas possibilidades.

Numa outra abordagem, Luís Carlos Freitas é enfático ao afirmar:

[...] devemos reconhecer que o "Estado avaliador" gerou (para poder formular políticas) uma enorme quantidade de dados sobre a educação em geral, nas bases de dados do governo. Eles não sabem muito bem o que fazer com estes dados - a não ser alimentar suas políticas. Acredito que devam sentir o problema crucial de não ter como consumir toda esta grande quantidade de dados e de não ter como fazer o usuário dos sistemas consumir toda esta informação.

Freitas tem dúvidas quanto a se os indicadores são necessários ou reveladores,

[...] pois os formatos de avaliação são simplificados (analisando-os do ponto de vista qualitativo) devido à amplitude da avaliação - e especialmente num país das dimensões do Brasil. No caso do ensino superior, substituiu-se o Programa de Avaliação Institucional das Universidades Brasileiras - Paiub -, que tinha uma perspectiva formativa, pelo Provão - e aí o nome já diz quase tudo. Reduziu-se a avaliação institucional à opinião do aluno combinada com visitas de comissões etc. No Estado de São Paulo temos o Saresp, que não foge à regra. Quanto a representarem as demandas sociais, é ainda mais duvidoso, a menos que entendamos por isso saber qual a demanda de vagas em escolas etc. Mas a demanda social é mais que isso: é uma demanda por tratamento isonômico e inclusão social.

Miriam Warde afirma que não tem estudado essas avaliações em particular, mas tem acompanhado as políticas do Estado de São Paulo e as federais: Num nível e noutro, as políticas têm sido traçadas independentemente das avaliações. Resta então saber a que e a quem os indicadores servem, bem como que espécie de realidade eles expressam.

Nesta mesma linha de pensamento, Gaudêncio Frigotto entende que o que se denomina avaliação não passa de "uma medida":

Provão, Enem e Saeb compõem uma trilogia que tem como base de avaliação ou medição, como declara abertamente a diretora do Inep e da Sesu, Maria Helena [Guimarães de] Castro, o que o mercado indica serem as competências. A 
educação "básica", isto é, aquela que fornece, como Gramsci nos indica, as bases de domínio da "sociedade dos seres humanos" e das coisas, reduz-se ao viés economicista. As próprias demandas sociais são orientadas por um discurso único veiculado pelos organismos oficiais e pelos aparelhos de hegemonia, dos quais a mídia é o principal. Um paradoxo claro na avaliação nacional é o de que, por lei, as escolas podem programar parte do seu currículo (25\%) com base em problemas e questões locais ou regionais. A avaliação, todavia, é um instrumento único para todo o país.

Aparecida Néri de Souza, por sua vez, aponta alguns problemas metodológicos de construção de indicadores educacionais:

Há um excessivo grau de generalizações. Penso que já abandonamos, em parte, a concepção de "escada" - quanto sobe (cresce) ou quanto desce (decresce). Entretanto, precisamos apreender as condições em que se realiza o trabalho escolar e suas variáveis qualitativas. Eu não afirmaria que temos segurança para analisar o que de fato acontece na escola brasileira. O real, creio que não é possível, mas sim se aproximar mais dele. E decorrente daí, eu diria que fazemos mais avaliações de desempenho das escolas (dos alunos mais que dos professores e diretores) $e$ menos avaliações das políticas educacionais.

Num segundo registro, a pesquisadora lembra que

[...] se pensarmos nas avaliações realizadas pelo próprio governo (como Saeb, Enem, Provão, Paiub, Capes), existe um conjunto de dados e indicadores que nos permitem compreender melhor a educação brasileira (há divulgação dos dados para os pesquisadores). As avaliações realizadas pelos centros de pesquisa (como NEPP/Unicamp ou Fundação Carlos Chagas), pela sua natureza (demanda dirigida), só podem ser acessadas com autorização governamental (essas avaliações são pouco disponíveis para os pesquisadores em geral). Se hoje temos no Brasil mais informações sobre a educação básica é pela grande contribuição dos programas de avaliação nacional e estaduais.

Quanto às avaliações educacionais apontarem as demandas sociais, a pesquisadora é da opinião de que elas "mais diagnosticam o desempenho dos programas e ações educacionais e trabalham menos com necessidades e pressões sociais. As avaliações (e seus desdobramentos na pesquisa acadêmica) são utilizadas para a formulação das políticas educacionais". A discussão sobre a concepção de demanda social, a seu ver, opera fortemente no campo da política.

De forma bem objetiva, Alicia Bonamino afirma que a política educacional da avaliação, ora em vigor no Brasil, deverá sofrer mudanças para melhor atender às demandas sociais em relação à educação básica. Diz a pesquisadora: 


\begin{abstract}
Nesse sentido, a transformação desse quadro e a continuidade do Saeb após a mudança de governo dependem de que a avaliação dos sistemas educacionais deixe de ser tratada como uma política do grupo no poder para transformar-se numa política de Estado. Isto significa que, no plano da política educacional, a possibilidade de que o Saeb venha a se tornar mais relevante para os gestores $e$ professores envolvidos com a educação básica depende de que sejam feitas algumas opções políticas chaves. Supõe, por exemplo, a tomada de decisões politicas e técnicas voltadas para o aprimoramento das medidas de origem socioeconômica e cultural dos alunos e para a melhoria da capacidade de apreensão das características escolares que minimizam o impacto da origem familiar dos alunos em seus resultados educacionais. Implica, também, a adoção de novas formas de apresentação dos procedimentos técnicos e dos achados do Saeb, que os tornem inteligíveis para não especialistas em pesquisas de levantamento em educação. A possibilidade de se avançar nesses aspectos está condicionada pela capacidade do Inep para estabelecer um novo padrão de interação com as secretarias de educação e com os professores, capaz de transcender a mera relação instrumental e de vir a propiciar um envolvimento efetivo destas instâncias com a política de avaliação. Por sua vez, isto depende da mobilização, pelo Inep, de recursos humanos e financeiros destinados à preparação de técnicos na área de avaliação capazes de dar suporte à interpretação dos resultados do Saeb e à formulação descentralizada de políticas educacionais públicas.
\end{abstract}

A última questão diz respeito ao possível esforço, por parte dos pesquisadores das ciências sociais (Sociologia da Educação), para a produção de trabalhos baseados nos resultados oferecidos pela avaliação da educação básica.

No entender de Luís Carlos Freitas, com base em alguns contatos informais mantidos com autoridades do governo, não há esse esforço por parte dos pesquisadores, apesar de os dados estarem disponíveis para análise. Diferentemente, Sandra Zákia Souza acredita que os dados avaliativos, bem como os resultados dos levantamentos estatísticos produzidos por instâncias governamentais, são utilizados pelos pesquisadores. Porém, ela não observa uma tendência à incorporação dos resultados da avaliação da educação básica (entendidos como o desempenho dos alunos nos testes, que é o que tem tido maior visibilidade pública).

Ivany Pino constata que as políticas de avaliação a partir das estratégias selecionadas respondem a interesses e em seguida questiona se esses interesses são os mesmos dos pesquisadores. O seu estranhamento refere-se ao fato de a base de dados do Inep, apesar de disponível, não ser requisitada pelas universidades.

Frigotto critica o fato de a avaliação ser usada pelo governo como mecanismo para penalizar aqueles que têm menor desempenho: 
Cria-se uma situação cínica. Um exemplo candente desta lógica cínica é o projeto Nova Escola protagonizado pelo governo do Estado do Rio de Janeiro. Contratou-se uma empresa privada de avaliação - Cesgranrio - para classificar as escolas mediante um conjunto de indicadores, de 1 a 5. As escolas com melhores condições de ensino e de infra-estrutura, supostamente, ganhariam 5, e, as piores, 1. Quem atinge a nota 1 recebe uma gratificação de 100 reais por mês trabalhado, já os que obtivessem grau 5 receberiam 500 reais. Essa gratificação é retirada em caso de doença e no período de férias do professor.

Completando seu pensamento, Frigotto afirma que poucos pesquisadores que têm uma base mínima de análise crítica utilizam os resultados das avaliações.

Diferentemente, Iza Locatelli vê a oferta de cursos de mestrado e doutorado como um indicador do crescimento dos estudos sobre avaliação. Da mesma forma, Creso Franco acredita que haja estudos nesse campo, salientando, porém, que se fazem necessários maiores esforços nesse sentido.

Para Miriam Warde, as políticas do Estado de São Paulo e as federais têm sido traçadas independentemente das avaliações. Resta então saber a que e a quem os indicadores servem, bem como que espécie de realidade eles expressam.

$\mathrm{Na}$ opinião de Aparecida Néri de Souza existe pouca produção analisando as avaliações, estrito senso. O que há são pesquisadores que acessam os dados (particularizam, fazem recortes) para contextualizar suas análises. Por exemplo, vamos aos dados para conhecermos alguns recortes de realidade, como funcionam as escolas, quem são os professores. No entanto, a pesquisadora reconhece que existem poucas análises sociológicas sobre as avaliações educacionais. Para Néri, os trabalhos da Ciência Política ou da Sociologia Política têm trabalhado mais com avaliações de políticas sociais do que os trabalhos da Sociologia da Educação. Diz a pesquisadora:

A análise de formulação e implementação de políticas, a análise de impacto e de processo, de relações de poder (negociação etc.), tem sido feita no campo da Ciência Política ou da Sociologia Política. Há também um trabalho sendo realizado na Pedagogia (mas dentro do campo da Administração), análises da avaliação como possibilidade de instrumento de planejamento e gestão."

Finalmente, Alicia Bonamino aponta a existência de dois fatores que concorrem para o fechamento do Inep e do campo da avaliação ao diálogo plural com as ciências sociais:

Por um lado, está a atual estrutura centralizada do Inep, que reforça a tendência à terceirização dos serviços do governo junto ao setor privado e incide na formação e manutenção de mercados especializados de avaliação, que descartam, por motivos 
ideológicos e financeiros, a participação da Universidade. Por outro lado, está o fato do Saeb ter tido pouca repercussão junto à Universidade, como se verifica no fato de que, afora a produção oficial, é quase inexistente a realização e divulgação acadêmica de estudos e pesquisas específicos sobre o tema. Com relação a esse segundo aspecto, devemos reconhecer que a falta de diálogo entre o Inep e a Universidade também se relaciona com a ausência de competências organizadas e articuladas na área pública no que se refere a estudos, pesquisas e execução de avaliações educacionais. A baixa capacidade técnica dos programas de pósgraduação, que, principalmente nos anos 80 , relegaram os estudos sobre avaliação $e$ as metodologias quantitativas a um plano marginal no contexto do ensino e da pesquisa, certamente também concorre para restringir as possibilidades de diálogo produtivo entre o campo da avaliação, as ciências sociais e a pesquisa.

\section{ALGUMAS CONSIDERAÇÕES}

Nos tempos atuais, há a preocupação com os problemas de ordens diversas apresentados pelo mundo escolar, tais como a efetiva democratização do ensino, a garantia da educação pelo Estado, a maior permanência dos alunos na escola tendo por objetivo um preparo mais eficiente para o exercício profissional e a cidadania.

Os pesquisadores se preocuparam em apontar as condições de inclusão escolar da massa populacional, como meio de enfrentar as múltiplas formas de dependência, alienação e exclusão social. Nesse sentido, as ciências sociais e a Sociologia da Educação tiveram um papel importante, ao estudarem a realidade e as suas possibilidades. Pouco a pouco, porém, o tema da eliminação das desigualdades deu lugar aos temas da eqüidade e da justiça nos sistemas escolares, e com eles inscreveram-se outros temas como a profissionalização dos professores, a socialização escolar dos jovens, o funcionamento das organizações escolares, os processos de decisão educativa ou o papel da família na educação dos filhos.

Quando solicitados a indicar os principais temas das pesquisas desenvolvidas no país no final dos anos 1980 e ao longo da década de 1990, os pesquisadores brasileiros entrevistados referiram a priorização dos temas intra-escolares. Eles admitem, contudo, que muitos trabalhos, principalmente na década de 1990, se debruçaram na análise da implementação das políticas públicas, tanto as locais quanto as nacionais, comparadas ou não, e na redefinição do Estado brasileiro em relação às questões sociais e educacionais.

Para os pesquisadores brasileiros entrevistados, os temas estudados nos últimos anos, como a cultura organizacional das escolas, o currículo escolar, as desigualdades como resultante das mudanças sociais, culturais e 
econômicas, o trabalho do professor para além das práticas pedagógicas, os estudos sobre a família e a escola e as representações que a família elabora sobre a escola, devem continuar a ser aprofundados.

No que diz respeito à influência das pesquisas sociológicas nas políticas públicas relativas à educação, a interpretação dos entrevistados brasileiros é a de que esta deve ter se dado de forma indireta e muito tênue, pois as pesquisas não atingem os professores. Não se pode deixar de reconhecer, contudo, que a partir do final dos anos 1980 um expressivo número de pesquisadores das ciências sociais - aqui entendida no seu sentido mais amplo - tem ocupado posições de destaque na gestão de sistemas educacionais.

É interessante chamar a atenção para o fato de que algumas pesquisas contemplaram o estudo das características da organização da escola como fator importante para avaliar a eficiência das instituições, ${ }^{7}$ as quais foram agrupadas com base em características supostamente capazes de auxiliar na realização dos objetivos pedagógicos. Dentre essas características encontra-se a avaliação dos conhecimentos adquiridos pelos alunos como forma de diagnosticar o real desempenho da escola.

Pouco a pouco, portanto, a avaliação educacional torna-se uma via importante para o diagnóstico das condições e da eficiência das instituições e das políticas públicas no cumprimento dos seus objetivos. Pode-se afirmar que tanto nos países desenvolvidos quanto nos países em desenvolvimento há uma crescente percepção da importância da avaliação educacional como instrumento fundamental não só para a implementação das políticas educacionais como também para o seu acompanhamento. Esta interpretação está ligada ao contexto socioeconômico imposto no plano mundial, que exige das sociedades grande urgência na revisão das suas políticas públicas. Nesse contexto, os gestores têm lançado mão da avaliação como um valioso recurso para acompanhar e formular propostas sociais em todos os setores. Enfim, pode-se afirmar que há um crescente interesse tanto nos meios educacionais quanto na política interna e também por parte de organismos internacionais em relação aos resultados do desempenho educacional, que podem ser tomados como indicadores nos estudos e análises de desenvolvimento e mobilidade social e de crescimento econômico.

No Brasil, a avaliação da educação básica é um tema que assume importância e urgência nas discussões, visto que a sua institucionalização deu-se a partir de 1990, quando a Secretaria Nacional de Educação Básica

7 Como exemplo, pode-se mencionar o trabalho de Nóvoa (1995) que cita as pesquisas de Pukey e Smith (1985); Reid Hopkins e Holly (1998); e o trabalho de Mediano (1998), que aponta autores como Arroyo (1995), Charlot (1996) e Mediano e Ludke (1995). 
destinou recursos para o primeiro ciclo do Sistema Nacional de Avaliação do Ensino Básico (Saeb). Esta foi a primeira de várias etapas avaliativas de larga escala, implementadas nos anos de 1993, 1995, 1997, 1999 e 2001, que foram sendo sucessivamente redimensionadas para atender a demandas cada vez mais complexas.

Bonamino (2000), percebe que embora, a partir de 1995, seja possível verificar sinais de avanços em relação às análises e aos instrumentos do Saeb, ainda é necessário corrigir a primazia que vem sendo dada às medidas educacionais e cognitivas, de modo a superar os resquícios de reducionismo pedagógico que o Inep o campo atual herdaram dos exercícios de avaliação conduzidos em 1990 e 1993 (p. 98). Segundo a autora, é um paradoxo o fato de o Inep não manter um diálogo mais intenso com as ciências sociais. O panorama atual assinala uma tendência à terceirização dos serviços do governo junto ao setor privado e a uma limitação no diálogo com as universidades. ${ }^{8}$

Alicia Bonamino faz duas suposições para justificar a limitação do papel atribuído às universidades pelo Inep. A primeira, tal como pensa Cury (1998), relaciona-se diretamente com a falta de articulação da avaliação com a pesquisa acadêmica, que ainda apresenta um pequeno número de estudos. A segunda suposição vincula-se à baixa capacidade técnica dos programas de pós-graduação, que relegaram os estudos sobre avaliação, bem como as metodologias quantitativas, a um plano pouco expressivo, tanto na pesquisa quanto no ensino.

Finalmente, Bonamino (2000) chama a atenção para a relação do Inep com as políticas oficiais:

No arranjo institucional dos tempos do Anisio [Teixeira], o Inep tinha uma certa autonomia com relação ao poder político, que propiciava aos cientistas e educadores envolvidos a possibilidade de manter um distanciamento crítico das políticas oficiais. Essa autonomia, que permitia o reconhecimento das ações institucionais como iniciativas do Estado, mas que limitava sua identificação como políticas de governo, está hoje ausente no Inep. Contrariamente a essa perspectiva, e provavelmente como forma de sofrer menos resistência e de ganhar maior agilidade,

8 Não obstante isso, Bonamino (2000, p. 98) chama a atenção para o Programa de Avaliação Educacional (PRO-AV) que, através de editais de chamada para pesquisa destinados a acadêmicos interessados em estudar diferentes aspectos da avaliação, tende a aproximar o Saeb da Universidade e a propiciar a formação de uma massa crítica no campo da avaliação, que já vem se traduzindo numa melhoria dos indicadores socioeconômicos e culturais dos alunos nos instrumentos contextuais do Saeb-99". 
a política do Inep no campo da avaliação vem sendo conduzida como uma política do governo central ou do grupo no poder. (p. 98)

Quando se pergunta aos pesquisadores brasileiros se a avaliação da educação básica, tanto no âmbito federal quanto no âmbito estadual, tem oferecido e divulgado indicadores que permitam analisar a real situação do ensino e indicar as principais demandas da sociedade, as respostas se dividem. É possível identificar dois grupos distintos: aqueles que concordam que as iniciativas de avaliação, apesar de recentes, têm fornecido indicadores que permitem ao pesquisador analisar a situação da educação básica, ainda que os trabalhos empíricos produzidos sejam poucos, e aqueles que não admitem essa contribuição das avaliações, pois colocam em dúvida a quem os indicadores por elas produzidos estão servindo, pois os objetivos educacionais nacionais não estão obrigatoriamente contidos nas avaliações. Essa posição leva a depreender que as reais necessidades e pressões sociais não são reveladas pelas avaliações. Assim, na esteira das fragilidades apresentadas pelos resultados da avaliação, muitos pesquisadores não se sentem estimulados a trabalhar com base nos dados oferecidos.

A pesquisa confirmou que o Brasil recebe influência temática de outros países nos estudos sobre a escola. Van Zanten (1999) observou a respeito da influência de trabalhos estrangeiros:

$\mathrm{Na}$ verdade, aqui se juntam os interesses dos pesquisadores, desejosos de compreender as implicações dessas mudanças para os agentes, e os interesses dos responsáveis pela educação, desejosos de, graças aos resultados das pesquisas sociológicas, poder envolver os agentes nessas mudanças e controlar seus possiveis efeitos negativos. Não se pode também descuidar da importância da pressão exercida pelos novos públicos universitários, futuros professores ou professores em exercício, para que os temas das pesquisas levassem em conta as preocupações cotidianas da "base" e para que os pesquisadores os auxiliem a superar as crises morais geradas por muitas dessas reformas. (p. 57)

Respeitadas as peculiaridades de cada país, pode-se dizer que a tendência dos trabalhos das ciências sociais brasileiras sobre educação produzidos nos anos 1980 e 1990 não se apresentou muito diferente daquela observada nos trabalhos da Sociologia da Educação francesa. Em ambos os países, os sociólogos da educação, voltados para dentro da escola - ao propor "abrir a caixa preta" das instituições escolares, da produção do saber escolar, das relações família/escola, do gerenciamento escolar etc. -, não perderam de vista os problemas das desigualdades escolares e sociais. Tanto na França como no Brasil, os trabalhos relativos ao mundo escolar 
têm na linha de mira a gênese das desigualdades macrossociais, mesmo que construídas em contextos e com metodologias diferenciadas. O Brasil tem proposto, nos últimos dez anos, a avaliação estatal, mas com um distanciamento muito grande dos atores educacionais - a quem, em última instância, as avaliações deveriam interessar como instrumento cotidiano de revisão dos objetivos educacionais - e também dos pesquisadores, em sua maioria vinculados às universidades.

Os fatores que concorrem para dificultar o relacionamento dos programas de avaliação com os estudiosos das ciências sociais são de natureza diversa. Dentre eles, certamente se destaca o fato de as decisões governamentais em matéria de avaliação tenderem a prescindir de um diálogo prévio com os atores educacionais. Como foi expresso por Bonamino (2000), a política de avaliação dos sistemas educacionais possui ainda o caráter de uma ação de governo, e não de uma ação de Estado. Essa característica repercute na própria legitimidade da avaliação e aumenta o risco de desarticulação do sistema avaliativo com a mudança dos dirigentes, aprofundando o sentimento de desconfiança por parte dos atores educacionais.

É preciso ainda ressaltar que a influência dos trabalhos produzidos na formulação das políticas públicas é certamente uma questão controversa. Quando se trata da influência das pesquisas no campo educacional no Brasil nos dias atuais, remete-se a discussão para a relação dos pesquisadores com órgãos de fomento governamentais e/ou com as universidades.

Sem dúvida, avaliar é preciso, mas há que priorizar a ação do Estado em favor da avaliação da educação básica no Brasil, para que a cultura da avaliação possa se fazer presente junto aos atores educacionais e beneficiá-los no cotidiano escolar, trabalhando em prol de uma educação democrática e de qualidade.

\section{REFERÊNCIAS BIBLIOGRÁFICAS}

BONAMINO, A. M. C. de. O Sistema Nacional de Avaliação da Educação Básica (Saeb): referências, agentes e arranjos institucionais e instrumentais. Rio de Janeiro, 2000. Tese (dout.). Pontifícia Universidade Católica do Rio de Janeiro.

CURY, C. R. J. Lei de Diretrizes e Bases e Perspectivas da Educação Nacional Democrática. Universidade e Educação. Campinas/São Paulo: Cedes/Anped/Andes, 1998. 
FRANCO, C. O Saeb: potencialidades, problemas e desafios. Revista Brasileira de Educação. Rio de Janeiro, v. 17, p. 127-133, 2001.

GATTI, B. A. A Produção da Pesquisa em Educação no Brasil e suas Implicações Sócio-Político-Educacionais: uma perspectiva na contemporaneidade. Comunicação apresentada na III Conferência Sociocultural. Campinas, 1620 de julho de 2000.

MEDIANO, Zélia. A Construção da Escola no Interior. Cadernos de Pesquisa, n. 103, p. 164-187, mar. 1998.

NÓVOA, António (coord.). As Organizações Escolares em Análise. 2.ed. Lisboa: Publicações Dom Quixote, 1995.

VAN ZANTEN, A. Saber Global, Saberes Locais: evoluções recentes da Sociologia da Educação na França e na Inglaterra. Revista Brasileira de Educação. Associação Nacional de Pós-Graduação em Educação (Anped), n. 12, set./out./nov./dez. 1999.

Recebido em: abril 2007

Aprovado para publicação em: agosto 2007 
